\title{
Effectiveness of 'Self Instructional Module' (SIM) On the Level of Knowledge Regarding Selected Minor Ailments and Their Remedial Measures among Pregnant Women
}

\author{
Mrs. Laxmi Kumar \\ (Lecturer, Obstetrics and Gynecology, Himalayan College of Nursing, Dehradun, India)
}

\begin{abstract}
Pregnancy is the most viewed from a physiological perspectives because of the dramatic physical changes the occurs throughout the pregnancy. Due to lack of knowledge of pregnancy related health problems, women often tends to ignore illness that is not very serious during pregnancy. A pre- experimental study was undertaken to assess the effectiveness of 'Self instruction module' (SIM) on the Knowledge of antenatal Mothers regarding minor ailments and their remedial measures in community health center in Uttarakhand. Total 60 antenatal mothers were selected by simple random sampling technique. The pre-test was taken by using structured knowledge questionnaire designed by researcher and validated by the various experts in the specific field followed by self Instructional module. After 7 days post-test was taken. The overall mean pre-test knowledge score of antenatal mothers was (18.16 \pm 4.8$)$ which reveals that mothers had good level of knowledge and mean post-test knowledge score of antenatal mothers was (25.3 \pm 4.3$)$ which revealed that mothers had very good level of knowledge and 't' value for total pretest and posttest was (8.6). Area wise post-test highest mean percentage was (74.3\%) in the area of remedial measures for nausea \& vomiting, backache and leg cramps and the lowest mean percentage was $(0.7 \%)$ in the area of minor ailments. No significant association was found between pretest knowledge scores with their demographic variables except educational status and type of family. The findings of the study concluded that 'Self Instructional module' (SIM) was effective to increase the knowledge of postnatal mothers regarding minor ailments and their remedial measures.
\end{abstract}

Keywords: Self Instructional module, Knowledge, Pregnant Mothers, Minor Ailments, Remedial measures

\section{INTRODUCTION}

Pregnancy is the normal healthy state; changes that occur in an expectant mother's body can produce a range of relatively minor but troublesome illness that is not very serious. As the pregnancy progresses the increasing size of the fetus produces physical stress on the body that can also give rise to uncomfortable symptoms. ${ }^{1}$

It is a proud moment and emotional experience for women to become a mother in her life. It is a special period that brings joys and pains. A common term used to describe pregnancy and child birth is very lucky. Nothing can compare to wonder of feeling a new life growing inside her yet with the wonder comes number of minor but distressing health complaints also accompany, such a morning sickness, heart burn, constipation, ankle edema, backache and so on. What can the expectant mother use that is safe for her unborn child as well as for herself. ${ }^{2}$

Wise woman believes that most of the problems of pregnancy can be prevented by attention to nutrition. Morning sickness and mood swings are connected to low blood sugar, backache and severe labor pain after results from insufficient calcium, varicose veins, hemorrhoids, constipation, skin discoloration and anemia are also related to lack of specified nutrition. ${ }^{3}$

Nausea and vomiting in pregnancy often termed pregnancy sickness, occurs in the first trimester in up to $80 \%$ of pregnancies. Recently nausea and vomiting in pregnancy is more likely to occur in individuals with high pre-conceptional Body Mass Index (BMI). The most common minor ailments is morning sickness, probably due to change in hormonal levels. Morning sickness is present in $50-80 \%$ of pregnant women. ${ }^{4,5}$

\subsection{Need of Study:}

Female literacy rate in India is $39.42 \%$ while in male is $63.86 \%$. Women are not aware of their fundamental rights. They are married in early stage. Their goal is to fulfill their husband's desire. Being married early they have no knowledge as to how progresses, the changes occurring and their remedial measures. In developing countries, once the girl reaches the age of puberty, the greatest threat to her life is pregnancy and child birth. In India $30-50 \%$ of teenage girls are married. In Bangladesh, $90 \%$ of the girls are married before the age of 18 years and 33\% are of mother of two children before the age of 19 years. $^{6}$ 
Most pregnancy related problem can be effectively prevented or managed without expensive technology or drugs. These problems can be resolved by providing health teaching to the communities regarding the management of those problems and acknowledging them about the accessible and quality health services. ${ }^{7}$

Many women experience some minor disorders during pregnancy; these disorders should be treated adequately as they become more serious. Minor disorders may occur due to hormonal changes, metabolic and postural changes. The women need to cope with knowledge \& cope with the experience of pregnancy. She also needs knowledge when she presents with discomforting or worrying symptoms. ${ }^{8}$

The nine months of pregnancy are special time of course, but its demands place the body of pregnant body under the great deal of stress and certain amount of discomfort is almost inevitable. Throughout pregnancy, she must be very cautious about using anything with a powerful pharmacological action that could have unknown effects on the body. She has to stick to very gentle remedies. She should always seek advice of her midwife or health visitor before treating any of the ailments herself. She should always consult doctor for the treatment of serious problems. ${ }^{9}$

While working in the community the investigator found that women during pregnancy are suffering from different minor ailments and are using various remedial measures among pregnant women. However, there had been many varied tradition and home remedies to relieve minor ailments of pregnancy existing in our culture but again literature is deficit in this regard. Therefore the study is planned to identify minor ailments and their remedial measures to manage pregnant women in our scenario. The finding of study may provide information to health professionals, administrators and planners so that culturally relevant interventional program can be planned and organized. If we want healthy mothers, fetus and healthy future, we should pay more attention towards the health status of mothers, only then we can think of better India tomorrow.

The investigator observed the limited knowledge of rural women and the poor practices of home remedies to relieve minor ailments in pregnancy. It was felt that home remedies practices were non beneficial. Hence, the investigator felt the need to assess the knowledge of pregnant women regarding home remedies practices and also to apprise how far these practices were beneficial to them. No systemic study was done on this topic and in the selected area. Thus it was expected that a study would help to impart knowledge regarding home remedies and its practices to prevent complications.

\subsection{Statement of Problem:}

A Pre experimental study to assess the effectiveness of self instructional module (SIM) on the level of knowledge regarding selected minor ailments and their remedial measures among pregnant women attending antenatal clinic in a selected community health centre at Dehradun, India. 2011

\subsection{Objectives:}

- To assess the pretest level of knowledge regarding minor ailments and their remedial measures among pregnant women.

- To assess the post level of knowledge regarding minor ailments and their remedial measures among pregnant women.

- To determine the effectiveness of self instructional module by comparing pretest and post test level of knowledge regarding minor ailments and their remedial measures among pregnant women.

- $\quad$ To find the association of post test knowledge score with their demographic variables.

\subsection{Hypothesis:}

$\mathbf{H}_{1}$ : There is a significance difference between pretest and post test level of knowledge.

H2: There is a significant association between the post test knowledge and demographic variables at the level of $\mathrm{P}<0.05$

\subsection{Conceptual Framework:}

The conceptual framework for the present study is based on nursing process model.

The conceptual framework of the present study is based on self-care theory of Dorothy Orem's (1985) “ The general theory of nursing" called self care deficit theory of nursing. Orem's general nursing theory is based on the three major concepts that is self care, self care deficit and nursing system.

Self-care deficit is the relationship between self care agency and therapeutic self care demands of individual with capabilities of self care. Therefore of existents limitation individual are not equal to meet some or all the components of therapeutic self care deficit. Inability to meet any of the 3 categories of self care requisite give rise to self care deficits. Thus a self care deficit is an ability to meet one's own therapeutic self care demands and those actions which are necessary to maintain function and promote development. In the present study, self care deficit area is the inability of the pregnant women to identify minor ailments and practice remedial measures for the same. 


\section{METHODOLOGY}

The research design used in this study was pre-experimental in nature. The study was conducted at community health center in Uttarakhand, INDIA. The sample of 60 pregnant women was selected by using simple random sampling technique. The tool used for the study was the structured knowledge questionnaire designed by the researcher consisting of section A (Socio- demographic variables such as age at marriage, age in current pregnancy, month in current pregnancy, educational status, occupation, type of family, monthly family income, place of living, gravida, previous exposure to any teaching and source of information. Section B (consisting of 40 items related to Knowledge regarding minor ailments and their remedial measures in three aspects i.e. nausea and vomiting, backache, leg cramps). The content validity of the tool was ensured by giving the tool to experts in the field of Nursing and Medical from Obstetrics and Gynecology, Community health nursing. A pilot study was conducted on 6 antenatal mothers in the selected primary health center. Reliability of tool was established by Karl Pearson's co-relation coefficient formula. The reliability of tool was calculated and it was $r=0.89$.

III. RESULTS AND FINDINGS

3.1 Related to Socio-Demographic Profile Pregnant women:

Table No.1: Socio-Demographic Profile of the pregnant women

\begin{tabular}{|c|c|c|}
\hline Sample Characteristics & Frequency (f) & Percentage $(\%)$ \\
\hline \multicolumn{3}{|c|}{ AGE OF MARRIAGE( IN YEARS) } \\
\hline $18-22$ & 42 & 70 \\
\hline $23-27$ & 18 & 30 \\
\hline $28-32$ & 00 & 00 \\
\hline \multicolumn{3}{|l|}{$33-37$} \\
\hline \multicolumn{3}{|l|}{ Above 38} \\
\hline \multicolumn{3}{|c|}{ AGE IN CURRENT PREGNANCY } \\
\hline \multicolumn{3}{|l|}{ ( IN YEARS) } \\
\hline $18-22$ & 20 & 35 \\
\hline $23-27$ & 28 & 45 \\
\hline $28-32$ & 11 & 18.3 \\
\hline $33-37$ & 00 & 00 \\
\hline Above 38 & 01 & 1.7 \\
\hline \multicolumn{3}{|c|}{ MONTH OF CURRENT PREGNANCY } \\
\hline 1-3 month & 13 & 21.7 \\
\hline 4-6 month & 17 & 28.3 \\
\hline 7-9 month & 30 & $\mathbf{5 0 . 0}$ \\
\hline \multicolumn{3}{|l|}{ EDUCATIONAL STATUS } \\
\hline Primary Education & 12 & 20 \\
\hline High school Education & 18 & 30 \\
\hline Intermediate $(10+2)$ & 19 & 31.7 \\
\hline Graduate $\&$ above & 11 & 18.3 \\
\hline \multicolumn{3}{|l|}{ OCCUPATION } \\
\hline Private employee & 05 & 8.3 \\
\hline Government employee & 03 & 5.1 \\
\hline Daily wages & 04 & 6.6 \\
\hline House wife & 48 & 80 \\
\hline \multicolumn{3}{|l|}{ TYPE OF FAMILY } \\
\hline Nuclear & 22 & 36.7 \\
\hline Joint & 38 & 63.3 \\
\hline \multicolumn{3}{|c|}{ MONTHLY FAMILY INCOME (IN RS.) } \\
\hline Below 3,000 & 5 & 8.3 \\
\hline $3001-6,000$ & 40 & 66.7 \\
\hline $6001-9000$ & 11 & 18.3 \\
\hline Above 9,000 & 04 & 6.7 \\
\hline \multicolumn{3}{|l|}{ PLACE OF LIVING } \\
\hline Urban & 09 & 15 \\
\hline Rural & 51 & 85 \\
\hline \multicolumn{3}{|l|}{ GRAVIDA } \\
\hline One & 31 & 51.7 \\
\hline Two & 24 & 40.0 \\
\hline Three & 05 & 8.3 \\
\hline Four \& above & 00 & 00 \\
\hline \multicolumn{3}{|c|}{ PREVIOUS EXPOSURE TO ANY HEALTH TEACHING } \\
\hline \multicolumn{3}{|c|}{ Yes } \\
\hline No & 14 & 23.3 \\
\hline SOURCE OF INFORMATION & 46 & 76.7 \\
\hline \multicolumn{3}{|l|}{ Family } \\
\hline Health workers & 08 & 13.3 \\
\hline Media & 19 & 31.7 \\
\hline & 33 & 55.0 \\
\hline
\end{tabular}




\section{$(\mathbf{n}=60)$}

The data shown in Table no.1 depicts the frequency and percentage distribution about the demographic variables according to the age of marriage of pregnant women, maximum 42(70\%) were in the age group of 1822 years and $18(30 \%)$ pregnant women belonged to $23-27$ years of age group.

$70 \%$ of subjects got married at the age group of $18-22$ years while only $18(30 \%)$ got married at the age of 23- 27 years. According to age in current pregnancy, most of the pregnant women 28(45\%) were in the age group of 23-27 years and only $1.7 \%$ pregnant women belonged to above 38 years of age.

Regarding educational status, most of the pregnant women $19(31.7 \%)$ were educated up to intermediate and 11(18.3\%) were graduate and above. As far as occupation is concerned, 48 (80\%) were housewives and only $3(5.1 \%)$ were government employee.

Regarding monthly family income, 40(66.7\%) pregnant women belonged to Rs.3001- 6,000 income group and $4(6.7 \%)$ belonged to above Rs.9,000 income group. Regarding place of living maximum 51(85\%) of pregnant women belonged to rural area and $9(15 \%)$ belonged to urban area.

Most of the pregnant women 31(51.7\%) were primi-gravida and 5(8.3\%) were grand multi-gravida. Regarding previous exposure to any health teaching $14(23.3 \%)$ were exposed to health teaching and 46(76.7\%) were not exposed to any health education.

\subsection{Comparing of pre and post test level of knowledge score regarding minor ailments and their remedial} measures among pregnant women.

Data presented in figure no. 1 depicts the grading of knowledge score at pretest and post-test level. In pretest $38 \%$ having moderate knowledge and $62 \%$ having inadequate knowledge. In post test $25 \%$ having adequate knowledge, $68 \%$ having moderate knowledge and $7.0 \%$ having inadequate knowledge. It could be inferred that teaching is the most effective method for improving the knowledge of pregnant women regarding minor ailments and their remedial measures.

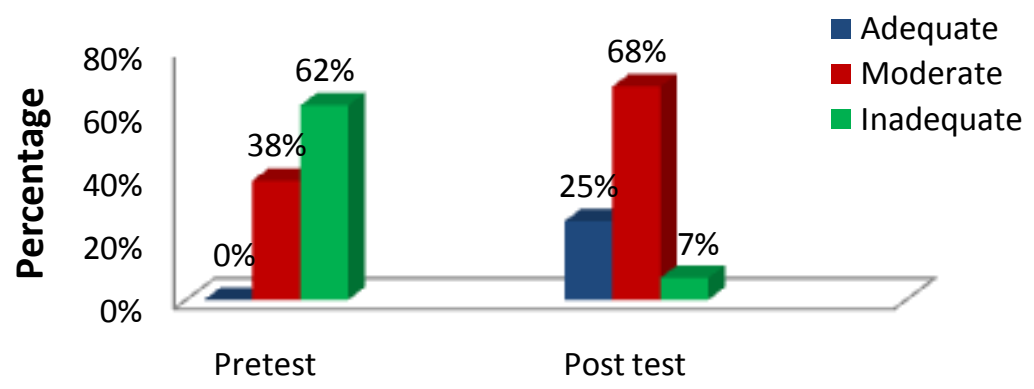

\section{Level of knowledge}

Fig No:1 Level of knowledge score regarding minor ailments and their remedial measures among pregnant women.

3.3 Effectiveness of self instruction module Knowledge regarding minor ailments \& their remedial measures among pregnant women:

Table No. 2: Pretest and post test knowledge score of pregnant women regarding minor ailments and their remedial measures.

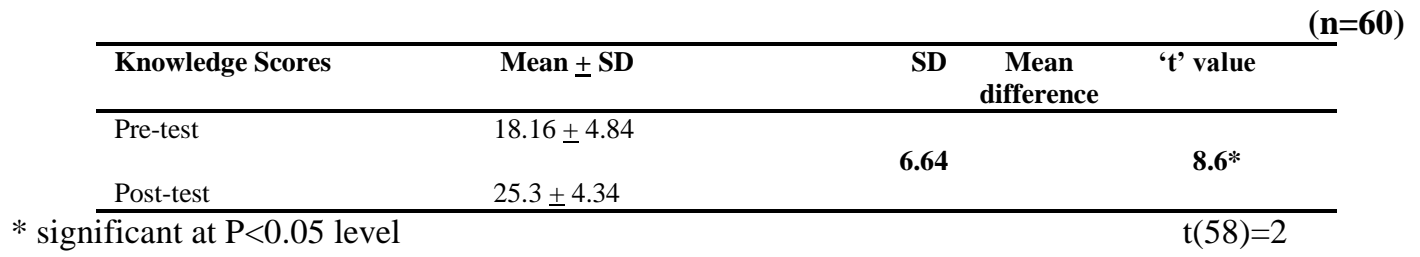

Table no. 2 shows that the mean of post-test knowledge score (25.3) of the pregnant women was higher than that of the mean of pre-test knowledge score (18.16). Hence the scores predicted that the significant difference between the mean of pre-test and post-test at $\mathrm{p}<0.05$ level. The research hypothesis $\left(\mathrm{H}_{1}\right)$ was accepted as the 
difference of mean observed was of significant difference and the 'self Instructional module' was effective to upgrade knowledge of pregnant women.

\subsection{Association between socio-demographic variables with knowledge of the pregnant women at post -test level}

Table No-3: Association between demographic variables with knowledge of pregnant women

\begin{tabular}{|c|c|c|c|c|}
\hline Demographic variables & Adequate & Moderate & Inadequate & $\chi^{2}$ \\
\hline 1.Age of marriage & & & & \\
\hline $18-22$ & 11 & 27 & 4 & \\
\hline $23-27$ & 4 & 14 & 0 & \\
\hline $28-32$ & 0 & 0 & 0 & 2.13 \\
\hline $33-37$ & 0 & 0 & 0 & \\
\hline Above 38 & 0 & 0 & 0 & \\
\hline \multirow{2}{*}{\multicolumn{5}{|c|}{ 2.Age in current pregnancy }} \\
\hline & & & & \\
\hline $23-27$ & 3 & 14 & 3 & \multirow{5}{*}{6.59} \\
\hline $28-32$ & 7 & 20 & 1 & \\
\hline $33-37$ & 5 & 6 & 0 & \\
\hline Above 38 & 0 & 0 & 0 & \\
\hline $\begin{array}{l}\text { 3.Month of current } \\
\text { pregnancy }\end{array}$ & 0 & 1 & 0 & \\
\hline $1-3$ month & 1 & 10 & 2 & \multirow{4}{*}{6.84} \\
\hline 4-6 month & 7 & 10 & 0 & \\
\hline 7-9 month & 6 & 22 & 2 & \\
\hline 4.Educational status & & & & \\
\hline Primary & 0 & 9 & 3 & \multirow{3}{*}{$28.01 *$} \\
\hline High school & 1 & 16 & 1 & \\
\hline Intermediate & 6 & 13 & 0 & \\
\hline Graduate $\&$ above & 8 & 3 & 0 & \\
\hline \multicolumn{5}{|l|}{ 5.Occupation } \\
\hline Private employee & 1 & 3 & 1 & \multirow{3}{*}{4.56} \\
\hline Govt. employee & 1 & 2 & 0 & \\
\hline Daily wages & 1 & 2 & 1 & \\
\hline House wife & 12 & 34 & 2 & \\
\hline \multicolumn{5}{|l|}{ 6.Monthly family income } \\
\hline Below 3,000 & 0 & 4 & 1 & \multirow{4}{*}{6.7} \\
\hline $3001-6,000$ & 7 & 30 & 3 & \\
\hline $6001-9,000$ & 4 & 7 & 0 & \\
\hline Above 9,000 & 2 & 2 & 0 & \\
\hline \multicolumn{5}{|l|}{ 7.Place of living } \\
\hline Urban & 3 & 6 & 0 & \multirow[t]{2}{*}{0.98} \\
\hline Rural & 12 & 35 & 4 & \\
\hline \multicolumn{5}{|l|}{ 8.Gravida } \\
\hline One & 4 & 25 & 2 & \multirow{3}{*}{6.29} \\
\hline Two & 6 & 16 & 2 & \\
\hline Three & 3 & 2 & 0 & \\
\hline \multirow{2}{*}{\multicolumn{5}{|c|}{$\begin{array}{l}\text { Four \& above } \\
\text { 9.Previous exposure to any } \\
\text { health teaching }\end{array}$}} \\
\hline & & & & \\
\hline Yes & 4 & 9 & 1 & \multirow[t]{3}{*}{0.038} \\
\hline & 11 & 32 & 3 & \\
\hline \multicolumn{4}{|l|}{ 10.Source of information } & \\
\hline Family & 3 & 4 & 1 & \multirow{3}{*}{3.08} \\
\hline Health workers & 3 & 14 & 2 & \\
\hline Media & 8 & 24 & 1 & \\
\hline
\end{tabular}

* significance at $\mathrm{P}<0.05$

Table no. 2 shows that only educational status was having statistical significant association with the post-test knowledge score at the level $\mathrm{p}<0.05$. Other Socio-Demographic variables like age of marriage, age in current pregnancy, month of current pregnancy, occupation, monthly family income, place of living, gravid, previous exposure to any health teaching, source of information statistically not having any association with post-test knowledge score at the level $p<0.05$.Hence, there was no evidence to reject null hypothesis for the variable age.

\section{NURSING IMPLICATIONS}

The findings of the study have implications in following fields.

\section{Nursing education}


- The community health nursing and obstetric nursing curriculum for all levels of nursing students should give more emphasis on promotion of health of pregnant women by controlling the discomforts related to minor ailments.

- Formal and informal teaching should be conducted in the antenatal clinic about minor ailments and their remedial measures.

- Continuing education should be provided to the nursing personnel regarding minor ailments and their remedial measures among pregnant women.

\section{Nursing service}

- Inservice education programme for the health workers and nursing personnel's must be carried out to improve their knowledge and teach clients for proper management of minor ailments.

- $\quad$ Research based nursing practice is a need of the hospital. On the basis of research, the hospital nursing care practices should be modified. Health education should be given to pregnant women regarding minor ailments.

\section{Nursing Administration}

Nursing has become a complex and highly varied practice discipline with the rapidly growing, well developed and well documented scientific and humanistic knowledge base.

- Nursing administration at hospital/ community level should evaluate the effectiveness of health programme related to pregnancy.

- Administration support should be provided to conduct inservice education programme for the nursing personnel's related to minor ailments.

- As a nurse practitioner and educationist, a self learning module or guidelines should have been prepared to teach the pregnant women regarding minor ailments and their remedial measures.

\section{Nursing Research}

Findings of the study will act as a catalyst or carry out more extensive research on a larger population, sample in different area of community. Through publication of the research findings, the knowledge of pregnant women regarding minor ailments can be improved which in turn helps early detection, prevention and control of minor ailments during pregnancy.

\section{CONCLUSION}

Conclusion was found derived from the findings of the study. It can be concluded that most of the pregnant women of community health center, Dehradun were from the age group of 23- 27 years. And most of them were got married in 18- 22 years. The most of the pregnant women were in 7-9 months of pregnancy period. Highest educational status of the pregnant women was intermediate among samples. Majority of pregnant women were housewives and most of them belonged to group who earn more than Rs. 3,000 per month. Majority of pregnant women belonged to joint family. Most of the pregnant women belonged to rural area and majority of pregnant women were in primi-gravida. Most of the pregnant women had not exposed to any health education and most of the pregnant women got information through media. In addition to pregnant women needs specific education design to help them to modify their life style and to take appropriate remedial measures to feel better and to reduce risk during pregnancy. Out of 60 pregnant women $25 \%$ were had adequate knowledge, $74.3 \%$ had moderate knowledge and $0.7 \%$ were had inadequate knowledge.

\section{ACKNOWLEDGEMENT}

"'Gratitude can never be expressed in words but this is only deep perception that makes the words to flow from one's inner heart" First and foremost, I would like to humbly thank almighty God for his divine interventions in my life without which I would not have been able to make this study.

A research project can never become successful without the coordinated efforts of members of the team. I have been very fortunate indeed to have valuable guidance by Mrs. Amita Shilpa Gottlieb as Guid and Mrs. Vasantha Kalyani as Co-Guide for their support and expertise. 


\section{REFERENCES}

[1] www. Health Izen. Com/pregnancy/index.aspx/healthizen.2009, last modified and reviewed 18/10/2010

[2] http:/www.babycenter.com/refcap/pregnancy/prenatalhealth/242.html.

[3] Hopkins John “Manual of Gynaecology and Obstetrics" $3{ }^{\text {rd }}$ edition, Lippincott Williams and Wilkins Publications. Philadelphia. P.No 232- 239

[4] Quinla JD, Hill DA. Nausea and vomiting of pregnancy. jdquilan@yahoo.com/ Review03.

[5] Susan G. Morning sickness. http:/WWW.bioband. com/morning sickness. Htm/review2006.

[6] Cooper. A. Fraserm Daina "Textbook of midwifes"14 $4^{\text {th }}$ edition. Daftary. N. Shirish. "Manual of Obstetrics" $2^{\text {nd }}$ edition. Reed elsvier India Pvt.Ltd. 2007; P.NO 63-67

[7] Bambewale. U. Family formation in India. Changes and continuity social Changes. 1992; 22 (3): 31-32. http:/www.amazingpregnancy.com/weekbyweek/complaints.htmlThe expecting mothers guide2007.

[8] Jacob. Annamma." A comprehensive textbook of midwifery”. $1^{\text {st }}$ edition. Jaypee brothers Pvt.(Ltd).N. Delhi 2005 P.No. $98-100$

[9] Macwan Brann. Common disorders of pregnancy.http:/www.sos disorders .com/index/htm/review0

\section{Other References}

[1] Leveno. Bloom. Gilstaap "William Obstetrics" 22 $2^{\text {nd }}$ edition. Medical Publication Division London. 1997 P.No $224-227$

[2] Lowder Milk Perry. "Maternity Nursing" $7^{\text {th }}$ edition. Reed elsivier India Pvt.(Ltd.) 2006 P.No 258 - 268

[3] Gabbe. Niebyl. Simpson “Obstetrics normal and problem pregnancies. $5^{\text {th }}$ edition. Churchill livingstone. 2002 P.No $1106-1185$

[4] Basavanthapa. B. T "Textbook of midwifery and reproductive health nursing. $1^{\text {st }}$ edition. Jaypee brothers Pvt.(Ltd) N. Delhi. 2006 P.No 212- 215

[5] Bobak. Jenson. “Maternity and Gynaecologic care” $2^{\text {nd }}$ edition St. Louis Mosby Year Book. 1993 P.No $244-245$

[6] Myles. "Textbook for Midwives" $13^{\text {th }}$ edition. Churchill livingstone. 1999,P.NO 203- 207

[7] Cunningham. Wenstrom. " Prenatal care in Williams Obstetrics " $22^{\text {nd }}$ edition. Mc Grow Hill companies Tornato ,2005 P.NO 201229

[8] Littletone, Engerbrestone. "Maternity Nursing Care" $7^{\text {th }}$ edition. Thompson Delmar learning Texas, 2007 P.NO 286- 292

[9] Kozier Barbara, Erb Glenora, Berman Audrey. Synder Shirlee. "Fundamentals of nursing." Conceptual Process and Practice, $7^{\text {th }}$ edition, Pearson education Delhi: 2004 P.NO 39- 40

[10] Jayasudha. A, “ Knowledge of pregnant women on warning signs during pregnancy" Nightingale Nursing Times, Volume5, No 12, March 2010. P.NO 51

[11] Shekhawat. Jeetender. Singh, "Home Remedies for selected common minor ailments" Nightingale Nursing Times. Volume6, No.2 May 2010 P. No 50- 54

[12] Suresh. Vasantha, "Safe Motherhood" Nightingale Nursing times" Volume 6, No. 2, May 2010 P.No 48

[13] Kaur. Manpreet, “ Compliance with prescribed treatment among antenatal women" Nightingale Nursing times, Volume 6, No 6, 2010 P.No 5

[14] Niebyl JR Goodwin TM, “ Overview of nausea and vomiting of pregnancy with an emphasis on vitamin and ginger" American journal of Obstetrics and Gynaecology, 2002 vol 186 No 5, P.NO S253- S255.

[15] Becken J. Ginger is preventing nausea and vomiting in pregnancy. The Pharmaceutical Journal. $1997 ; 270$ (42): $163-164$.

[16] www.webmed central. Com/prevalence of gastrointestinal symptoms in pregnancy review/526.

[17] http://www. Clinical evidence.com/nausea and vomiting in pregnancy/review06.

[18] American Academy of family physicians. Backache in pregnancy: what should know. April 2005. http:/familydoctor.org/800.xml.

[19] Mayo clinic. Muscle cramp. August 2004. http:/www.mayoclinic. com/invoke.cfm?id=DS00311.

[20] MarchofDimes.Legcramps. http:/www.marchofdimes.com/pnhec/159_15292asp.

[21] http:/www.ayurveda-herbal-remedy.com/homeremedies/home-remedies-backpain.html

[22] http:/www.nvp-volumes.org/p2-prevalence and severity of nausea and vomiting of pregnancy and effects.html

[23] http:/www.patient.co.uk/doctor/nausea and vomiting in pregnanacy.

[24] http:/www.ajog.org/article/0002-9378(95)90186-8/abstract-The effect of oral magnesium substitution on pregnancy-induced legcramps. 